\title{
The Impact of a Concierge Medicine Model on Door to Doctor Time and Patient Flow in an Urban Emergency Department
}

This article was published in the following Dove Press journal: Open Access Emergency Medicine

\author{
Asher L Mandel \\ Thomas Bove \\ Amisha D Parekh \\ Paris Datillo \\ Joseph Bove Jr \\ Linda Bove \\ Joseph J Bove \\ Robert H Birkhahn
}

Department of Emergency Medicine, New York Presbyterian Brooklyn Methodist Hospital, Brooklyn, NY, USA
Introduction: Emergency Department (ED) crowding negatively impacts patient outcomes, patient satisfaction, and patient safety. One solution involves introducing a Concierge Physician (CP) whose sole purpose is to provide a brief initial assessment (BIA) and aid patient navigation through the ED. The goal of this study was to quantify the impact of a CP on patient flow dynamics in an urban ED setting.

Methods: We performed a retrospective observational cohort study in an urban academic ED over a 6-month period. Initially, the $\mathrm{CP}$ was present in the treatment area during weekdays; during the last half of the observation period, an additional $\mathrm{CP}$ was added to the waiting room on weekends. We identified four major milestones in the ED visit with regards to patient throughput. Adult patients presenting to the ED with a triage level of Urgent (ESI 3) were analyzed for this study. Data were stratified based on the patient's ultimate disposition (admitted or discharged) and presented as means with predictive analysis.

Results: Between August 2016 and January 2017, the ED evaluated 42,397 adult patients. Of those, 26,976 (64\%) were triage level Urgent (3). Of the level 3 patients, 10,279 (38\%) received a BIA from a $\mathrm{CP}$. Patients evaluated by a $\mathrm{CP}$ were seen approximately 30 mins faster ( $40 \%$ reduction in Door to Doctor time), but stayed 30 mins longer in the ED on average, because the medical decision-making process took $>1 \mathrm{hr}$ longer when the patient was initially evaluated by a CP.

Conclusion: Adapting a concierge medicine model to rapidly evaluate patients resulted in a dramatically reduced Door to Doctor time, but an increase in overall time spent in the ED. This discrepancy was a direct result of the delay in physician disposition.

Keywords: metrics, Door to Doctor time, administration

\section{Introduction}

In the United States, demand for emergency department (ED) services is increasing rapidly. ${ }^{1}$ This increase in patient volume has led to ED crowding, which negatively impacts patient outcomes, patient satisfaction, and patient safety. ${ }^{2-4}$ Other adverse consequences include an increasing number of patients who leave before being seen, as well as treatment of patients in unfavorable patient care environments laying in beds in hallways and sitting in chairs when no beds are available. ${ }^{5,6}$

In 2014, the Centers for Medicare and Medicaid Services published ED throughput quality measures to assess an ED's timeliness of care. ${ }^{7}$ One such measure is Door to Doctor, which quantifies the time between a patient's registration in the ED and their
Correspondence: Robert $\mathrm{H}$ Birkhahn Department of Emergency Medicine, New York Presbyterian Brooklyn

Methodist Hospital, Brooklyn, NY II215, USA

Tel + I 7187805040

Fax +I 7187803153

Email birkhahn@doctoris.org 
initial encounter with a licensed ED physician. It has been shown that decreased Door to Doctor time can lead to shortening of the overall length of stay. ${ }^{8}$ Decreasing throughput times, while maintaining high-quality treatment standards, can alleviate ED crowding and its associated issues.

Several methods have been suggested to decrease throughput times for patients. ${ }^{9}$ One solution is the Banner Health Door To Doctor Split-Flow Design. In this design, patients are split into two groups - the "most sick" and the "least sick". The "least sick" are kept in their clothing and remain ambulatory for quicker disposition, which keeps beds available for patients who really need them and are likely to be admitted to the hospital. ${ }^{10}$

Another solution proposed to decrease throughput times in the PIT (Provider in Triage) model. In the PIT model, a physician is stationed in the triage area and seeks to expedite care through rapid orders, interventions, and bringing acute patients to a bed. ${ }^{11,12}$ Some successful renditions of this model have utilized a multidisciplinary PIT team: including a PIT nurse and PIT nurse tech. ${ }^{13}$

A third solution presented to decrease throughput times, and the focus of this study, is the implementation of a Concierge Physician (CP). As used in Clark's 2013 paper, ${ }^{5}$ the $\mathrm{CP}$ was an ED physician who was called into the ED during times of overcrowding outside of that physician's normal shift schedule. This study used a variation on that type of CP in that the CP was not called in response to a system stress but rather was given a scheduled work shift on a rotating basis to address ED crowding.

In this study, the CP provided a brief initial assessment (BIA) and aided patient navigation through the ED. The $\mathrm{CP}$ was an emergency-medicine-trained physician who identified and approached patients (either in the waiting room or who had already been triaged and were waiting for formal evaluation inside the main ED) and initiated testing: including lab work and radiographic imaging. In so doing, the CP reduces the Door to Doctor window, in the hopes of reducing overall length of stay. The goal of this study was to quantify the impact of a $\mathrm{CP}$ on patient flow dynamics in the ED setting.

\section{Materials and Methods}

We performed a retrospective observational cohort study in New York-Presbyterian Brooklyn Methodist Hospital ED. All available records during a 6-month period with a Concierge Physician evaluation were reviewed. The 6-month window was chosen after the CP model had been introduced to the ED for a run-in period of 6 months and chosen to be during the busiest part of the year when crowding was historically the worst (August - January). We excluded patients from the study who expired, were immediately transferred to another facility, or refused treatment. Initially (August-October), one CP was present in the treatment area during weekdays and occasional weekends. During the last half of the observation period (NovemberJanuary), an additional CP was added to the waiting room on all weekends. This study involved the evaluation of a deidentified administrative dataset and qualified for exemption from institutional review board (IRB) review.

New York-Presbyterian Brooklyn Methodist Hospital is located in the urban Park Slope neighborhood of Brooklyn and is a teaching, academic, and communitybased hospital. The ED is composed of 4 sections: the Adult ED, SMART (Simple Medical Assessment Rapid Treatment), the Pediatric ED, and the Rapid Evaluation Unit (commonly referred to elsewhere as "fast-track"). The Adult ED has 48 patient care areas: 5 trauma rooms, 4 OBGYN rooms, 6 respiratory chairs, 1 psychiatry room, 3 negative pressure isolation rooms, and 29 "doubled up" rooms that each has 2 beds; in addition, SMART (an adjunct of the Adult ED) has 2 triage rooms and 3 treatment rooms. The Rapid Evaluation Unit is an offshoot of the waiting area and consists of 6 treatment rooms. The Pediatric ED was excluded from this study.

During the study window, the Adult ED was staffed by 4 residents (with 2 rotating off-service residents), 2 teaching attendings, 3 clinical attendings who treated patients without a resident physician, and 1 Concierge Physician. Patients with a triage level of 1 or 2 were seen by an acute care team, while patients with triage levels 4 and 5 were seen by mid-level providers. Adult patients, presenting to the ED with a triage level of Urgent (ESI 3), were analyzed for this study. Upon registration and triage as a level 3 patient: the $C P$ saw the patient, wrote a BIA, and submitted relevant orders.

We identified four major windows of time in the ED visit with regards to patient throughput: Door to Doctor, Door to Decision, Doctor to Decision, and Door to Disposition. "Door" is the moment that the patient is registered in the ED. "Doctor" is the moment a treating clinician (resident or attending physician) sees the patient, whether it is a BIA or not. "Decision" is the moment when the treating clinician puts in the order for discharge or admission. Finally, "Disposition" is the moment the patient physically leaves the ED. All time intervals were captured in the electronic medical record and recorded in real time, however the data were abstracted retrospectively. The data were stratified 
based on patient's ultimate disposition (admitted or discharged).

For each measure, such as Door to Doctor time, a breakdown by categorical variables was first performed. For example, Door to Doctor time was broken down as a function of Weekend (Yes or No) or as a time block (midnight to $6 \mathrm{AM}$, etc.). The median and mean times for each measure, by each category, were computed along with its standard deviation. For each measure, and by each categorical variable, if the categorical variable was dichotomous, a $t$-test for differences in the means for each category was performed. If the categorical variable had more than two levels, an ANOVA test for differences in means was conducted.

Next, a Bayesian regression using each of the categorical variables was performed, one per categorical variable. The regressions were performed on $\mathrm{R}$ (version 3.4.4), using the rstanarm package (version 2.17.4), using default or "noninformative" priors on the parameters. ${ }^{14}$ Each regression was then cast into its predictive form. ${ }^{15-17}$ This gives the predictive probability of any Door to Doctor time or interval as a function of the categorical variable.

The predictive distributions of each regression (Table 1) were used to calculate the probability the times in one category were greater than in another category. For instance - for Doctor to Decision time - the regression on the dichotomous

Table I Measured Time Intervals Stratified by Presence of a Brief Initial Assessment

\begin{tabular}{|c|c|c|c|c|}
\hline \multicolumn{5}{|c|}{ Door To Doc } \\
\hline BIA & Median & Mean & SD & $\operatorname{Prob}\left(\operatorname{Lev} \_j>\right.$ Lev_I) \\
\hline $\mathrm{N}$ & 62.4 & 83.4 & {$[70 . .3]$} & 0.5 \\
\hline Y & 29 & 48.9 & {$[51]$} & 0.359 \\
\hline \multicolumn{5}{|c|}{ Doc To Decision } \\
\hline BIA & Median & Mean & SD & $\operatorname{Prob}\left(\operatorname{Lev} \_j>\right.$ Lev_l $)$ \\
\hline$N$ & 176 & 198 & {$[133]$} & 0.5 \\
\hline$Y$ & 241 & 265 & {$[173]$} & 0.618 \\
\hline \multicolumn{5}{|c|}{ Door To Decision } \\
\hline BIA & Median & Mean & SD & $\operatorname{Prob}\left(\operatorname{Lev} \_\right.$j>Lev_I) \\
\hline $\mathrm{N}$ & 259 & 280 & {$[147]$} & 0.5 \\
\hline Y & 294 & 314 & {$[217]$} & 0.547 \\
\hline \multicolumn{5}{|c|}{ Door To Disposition } \\
\hline BIA & Median & Mean & SD & $\operatorname{Prob}\left(\operatorname{Lev} \_j>\right.$ Lev_I) \\
\hline $\mathrm{N}$ & 345 & 407 & {$[276]$} & 0.5 \\
\hline Y & 378 & 439 & [27I] & 0.521 \\
\hline
\end{tabular}

Table 2 Characteristics by Patient Cohort

\begin{tabular}{|c|c|c|c|c|c|}
\hline \multirow[t]{2}{*}{ Age } & \multirow[t]{2}{*}{ Total } & \multicolumn{2}{|c|}{$\mathbf{B} \mid \mathbf{A}=\mathbf{N}$} & \multicolumn{2}{|c|}{$B \mid A=Y$} \\
\hline & & $\mathbf{N}$ & $\%$ & $\mathbf{N}$ & $\%$ \\
\hline$[18 ; 65]$ & 19,170 & 11,923 & [71.4] & 7247 & [70.5] \\
\hline$[65 ; 106]$ & 7806 & 4774 & [28.6] & 3032 & [29.5] \\
\hline \multicolumn{6}{|l|}{ Triage Time } \\
\hline PM & 17,450 & 8345 & [50] & 9105 & [88.6] \\
\hline AM & 9526 & 8352 & [50] & 1174 & [II.4] \\
\hline \multicolumn{6}{|l|}{ Disposition } \\
\hline Admitted & 8177 & 4955 & [29.7] & 3222 & [31.3] \\
\hline Discharge & 18,799 & 11,742 & [70.3] & 7057 & [68.7] \\
\hline
\end{tabular}

variable, "BIA", allowed us to calculate the predictive probability that Doctor to Decision times would be greater for a patient with a BIA compared to one without a BIA. Stated another way, given the model and observed data, we estimate there is a $61.8 \%$ chance that Doctor to Decision would be greater for a patient with a BIA than for one without a BIA.

This is superior to statistical testing because tests only say if differences exist "significantly", whereas the predictive analysis allows us to quantify the chance differences will persist. The predictive method thus allows the results from the analysis to be stated in plain English and in a decisive form, with the assumption that our data would be similar to data observed at other locations. ${ }^{15-17}$

\section{Results}

Between August and January, the ED evaluated 42,397 adult patients. Of those, 26,976 (64\%) were triage level Urgent (3). Of the level 3 patients, $10,279(38 \%)$ received a BIA from a Concierge Physician. A breakdown of the demographics of the patient population can be seen below in Table 2 .

Table 1 presents the predictive analysis for how likely it was that a patient with a BIA (Y) had a longer throughput time than a patient without a BIA (N).

Table $3 \mathrm{~A}$ and $\mathrm{B}$ present a more in-depth breakdown of throughput mean times. 1 standard deviation above and below the means is presented parenthetically. 3A presents data from all days, while $3 \mathrm{~B}$ presents data from patients seen exclusively on weekends. This was done to further isolate the effects of the added $\mathrm{CP}$ on weekends in the second half of the study window.

\section{Discussion}

The biggest difference between our model and PIT is the extent of staffing. We took an already-crowded ED with 
Table 3 Clinical Care Milestones Stratified by Presence of Brief Initial Assessment and Patient Disposition

\begin{tabular}{|c|c|c|c|c|c|}
\hline \multicolumn{6}{|l|}{$\mathbf{A}$} \\
\hline \multicolumn{2}{|l|}{ All Days } & \multirow{2}{*}{$\begin{array}{l}\begin{array}{l}\text { Door to } \\
\text { Doctor (Hrs) }\end{array} \\
1.48(1.43,1.53)\end{array}$} & \multirow{2}{*}{$\begin{array}{l}\text { Door to } \\
\text { Decision (Hrs) } \\
5.17(5.07,5.27)\end{array}$} & \multirow{2}{*}{$\begin{array}{l}\begin{array}{l}\text { Doctor to } \\
\text { Decision (Hrs) }\end{array} \\
3.75(3.66,3.84)\end{array}$} & \multirow{2}{*}{$\begin{array}{l}\begin{array}{l}\text { Door to Disposition } \\
\text { (Hrs) }\end{array} \\
10.10(9.88,10.32)\end{array}$} \\
\hline $\begin{array}{l}\text { Aug-oct, Concierge in Treatment } \\
\text { area }\end{array}$ & $\begin{array}{l}\text { Admitted Without } \\
\text { BIA }(n=2636)\end{array}$ & & & & \\
\hline & $\begin{array}{l}\text { Discharged Without } \\
\text { BIA }(n=6069)\end{array}$ & $1.54(1.51,1.58)$ & $4.62(4.56,4.68)$ & $3.08(3.03,3.14)$ & $5.22(5.14,5.29)$ \\
\hline & $\begin{array}{l}\text { Admitted with BIA } \\
(n=1466)\end{array}$ & $1.00(0.95,1.05)$ & $5.90(5.62,6.18)$ & $4.91(4.63,5.18)$ & $10.64(10.38,10.89)$ \\
\hline & $\begin{array}{l}\text { Discharged with BIA } \\
(n=3 \mid 95)\end{array}$ & $0.86(0.83,0.90)$ & $5.29(5.20,5.38)$ & $4.43(4.35,4.5 I)$ & $5.81(5.71,5.95)$ \\
\hline \multirow[t]{4}{*}{$\begin{array}{l}\text { Nov-Jan, Concierge in Treatment } \\
\text { and waiting Room }\end{array}$} & $\begin{array}{l}\text { Admitted Without } \\
\text { BIA }(n=2328)\end{array}$ & $\mathrm{I} .28(\mathrm{I} .24, \mathrm{I} .32)$ & $5.30(4.93,5.12)$ & $3.78(3.69,3.87)$ & $10.92(5.71,5.92)$ \\
\hline & $\begin{array}{l}\text { Discharged Without } \\
\text { BIA }(n=5677)\end{array}$ & $1.34(1.31,1.37)$ & $4.47(4.4 \mathrm{I}, 4.53)$ & $3.13(3.08,3.19)$ & $5.08(5.00,5.15)$ \\
\hline & $\begin{array}{l}\text { Admitted with BIA } \\
(n=\mid 756)\end{array}$ & $0.88(0.85,0.92)$ & $5.59(5.45,5.69)$ & $4.68(4.57,4.80)$ & II.42 (II.6, II.68) \\
\hline & $\begin{array}{l}\text { Discharged with BIA } \\
(n=3872)\end{array}$ & $0.80(0.77,0.82)$ & $4.95(4.88,5.02)$ & $4.15(4.10,4.22)$ & $5.48(5.40,5.57)$ \\
\hline \multicolumn{6}{|l|}{ B } \\
\hline \multicolumn{2}{|l|}{ Weekends only } & $\begin{array}{l}\text { Door to } \\
\text { Doctor (Hrs) }\end{array}$ & $\begin{array}{l}\text { Door to } \\
\text { Decision (Hrs) }\end{array}$ & $\begin{array}{l}\text { Doctor to } \\
\text { Decision (Hrs) }\end{array}$ & $\begin{array}{l}\text { Door to Disposition } \\
\text { (Hrs) }\end{array}$ \\
\hline \multirow[t]{4}{*}{$\begin{array}{l}\text { Aug-Oct, Concierge in Treatment } \\
\text { area }\end{array}$} & $\begin{array}{l}\text { Admitted Without } \\
\text { BIA }(n=6 \mid 9)\end{array}$ & $1.56(1.47,1.66)$ & $5.21(5.03,5.40)$ & $3.70(3.54,3.86)$ & $9.11(8.78,9.44)$ \\
\hline & $\begin{array}{l}\text { Discharged Without } \\
\text { BIA }(n=1911)\end{array}$ & $1.74(1.68,1.80)$ & $4.80(4.69,4.92)$ & $3.07(2.97,3.16)$ & $5.38(5.25,5.4 \mathrm{I})$ \\
\hline & $\begin{array}{l}\text { Admitted with BIA } \\
(n=194)\end{array}$ & I.65 $(1.49,1.80)$ & $6.42(6.06,6.77)$ & $4.80(4.47,5.13)$ & $10.28(9.46,10.92)$ \\
\hline & $\begin{array}{l}\text { Discharged with BIA } \\
(n=434)\end{array}$ & $1.74(1.65,1.83)$ & $5.86(5.63,6.09)$ & $4.13(3.92,4.34)$ & $6.40(6.13,6.66)$ \\
\hline \multirow[t]{4}{*}{$\begin{array}{l}\text { Nov-Jan Concierge in Treatment } \\
\text { and waiting Room }\end{array}$} & $\begin{array}{l}\text { Admitted with BIA } \\
(n=535)\end{array}$ & $\mathrm{I} .33(\mathrm{I} .24, \mathrm{I} .4 \mathrm{I})$ & $5.09(4.88,5.29)$ & $3.78(3.59,3.96)$ & $9.01(8.60,9.42)$ \\
\hline & $\begin{array}{l}\text { Discharged Without } \\
\text { BIA }(n=1594)\end{array}$ & I.34 (I.29,I.39) & $4.46(4.35,4.57)$ & $3.13(3.03,3.24)$ & $5.07(4.94,5.19)$ \\
\hline & $\begin{array}{l}\text { Admitted with BIA } \\
(n=329)\end{array}$ & $1.20(1.11,1.29)$ & $5.87(5.6 I, 6.13)$ & $4.67(4.42,4.93)$ & $9.57(9.12,10.02)$ \\
\hline & $\begin{array}{l}\text { Discharged with BIA } \\
(n=798)\end{array}$ & $1.21(1.15,1.27)$ & $5.33(5.17,5.48)$ & $4.11(3.96,4.26)$ & $5.96(5.77,6.13)$ \\
\hline
\end{tabular}

long Door to Doctor times and just added an extra physician to the schedule. The presumption was that they would order needed tests more quickly and this would lead to earlier dispositions. The reality was that the Door to
Doctor metric was decreased, but without more staff (nurses and technicians), the system got overloaded with tests and was not able to perform them any faster than before. 
This trend is reflected in Table 1, along with predictive analyses for each throughput times. Overall, patients with a BIA had decreased Door to Doctor metric, but increased times in every other metric thereafter. More specifically, patients with a BIA had a $35.9 \%$ chance of increased Door to Doctor than those without a BIA. Said differently, the patients with a BIA had a $64.1 \%$ chance of decreased Door to Doctor. Patients with a BIA had a $61.8 \%$ chance of increased Doctor to Decision. Patients with a BIA had a $54.7 \%$ chance of increased Door to Decision. Lastly, patients with a BIA had a $52.1 \%$ chance of increased Door to Disposition.

On analysis of "all days" in the observation period (Table 3A): patients evaluated by a CP were seen approximately 30 mins faster (40\% reduction in Door to Doctor time), but stayed 30 mins longer in the ED on average, because the medical decision-making process took $>1 \mathrm{hr}$ longer when the patient was initially evaluated by a CP.

As seen in the top half of Table 3A, from August to October - Door to Doctor window was shorter for patients with BIA (vs no BIA) by approximately 30 mins for both admitted and discharged patients. Door to Decision was increased by about 45 mins. Doctor to Decision increased by more than an hour. Door to Disposition increased by a little more than 30 mins. Thus, although the patients' initial contact with a physician was sped up through the employment of a $\mathrm{CP}$, the overall length of stay actually increased. If we look at the bottom half of Table $3 \mathrm{~A}$ (November - January) in isolation from the top half, the conclusions are similar. For example: Door to Doctor decreased by about 30 mins, Door to Decision increased by 30 mins and so on. The results do not reflect favorably on the efficacy of the $\mathrm{CP}$, which was intended to reduce the overall length of stay in addition to reducing Door to Doctor.

However, if we juxtapose all of the means from Table $3 \mathrm{~A}$ in August - October against their corresponding means from November - January, a different story emerges. The vast majority of means in the bottom half of the table are smaller than their corresponding data points in the top half, except for 4 instances - Doctor to Decision for patients without a BIA and Door to Disposition for admitted patients with and without BIA. However, the margin in Door to Decision is less than 3.5 mins. Thus, on the whole, the throughput times for level 3 adult patients between November and January were less than those seen between August and October. We see through this blanket comparison that, in the period where an additional $\mathrm{CP}$ was present in the waiting room, patients in the ED were processed and treated more quickly. The ED saw comparable volumes of patients in these two periods, so variation in ED business is not the factor that differentiates these two periods.

This reduction in throughput times is not limited to patients seen exclusively by the $\mathrm{CP}$, but it applies to the $\mathrm{ED}$ as a whole. Having the additional $\mathrm{CP}$ present on weekends did not only reduce Door to Doctor and Door to Decision for patients with a BIA, but it also reduced these throughput times for patients without a BIA. This finding suggests that the presence of a $\mathrm{CP}$ within the $\mathrm{ED}$ framework is augmenting the overall efficiency of the ED - speeding up level 3 patients' initial processing and allowing other team members to attend to other patients more efficiently as well.

This point is further corroborated by the analysis of Table 3B, which isolates the data to weekends-only. The same trend as seen in Table 3A appears in 3B with regards to the isolate analyses of BIA vs no BIA of the top and bottom halves, respectively. Yet here, the blanket comparison is even more clearly demonstrating CP's efficacy. In only two means (in Doctor to Decision for non-BIA patients) are the throughput times higher for patients in the second half of the observation period (with an additional CP) and the margin is less than 5 mins. On the whole, patients' throughput times were decreased when the additional CP was present in the waiting room on weekends.

In summary, while Door to Doctor decreased, the rest of the throughput measures increased for patients with a BIA. We can speculate that these increases are due to increased testing ordered by the $\mathrm{CP}$ and consequently, increased time for staff to execute those orders and also increased time discussing results with the patient at the end of the visit: however, the scope of this study did not allow for this level of analysis.

The primary limitation of this study is the lack of patient-level data regarding the ED visits. In other words, it is not clear what caused the delay after the CP evaluated the patient. If information was included that delineates which tests were ordered for which patients, we may have been able to identify correlations between tests/studies ordered for certain patient presentations and longer ED lengths of stay.

Further analysis may be useful to look at the costbenefit ratio of employing an additional emergency physician in light of the impact on throughput metrics. Although there is a clear benefit in reduced door to doctor time, there is a need to address back-end medical decision-making 
and ancillary support that appears to limit the utility of the $\mathrm{CP}$ model in our practice environment.

\section{Conclusion}

Adapting a concierge medicine model to rapidly evaluate patients resulted in a dramatically reduced Door to Doctor time, but slightly longer overall time spent in the ED. This discrepancy was a direct result of the delay in physician disposition. This delay represents discordance in medical decision-making and needs to be remedied before the CP can be recommended as an effective form of patient navigation.

\section{IRB}

This work involved an administrative dataset that used deidentified patient data and was exempt from IRB review.

\section{Acknowledgment}

The abstract of this paper was presented at the Research Forum of the American College of Emergency Physicians as a poster presentation with interim findings. The poster's abstract was published in "Poster Abstracts" in Annals of Emergency Medicine: Volume 70, Issue 4, Supplement.

\section{Disclosure}

The authors report no conflicts of interest in this work.

\section{References}

1. Bellow AA, Gillepsie GL. The evolution of ED crowding. J Emerg Nurs. 2014;40(2):153-160.

2. Pines JM, Hollander JE. Emergency department crowding is associated with poor care for patients with severe pain. Ann Emerg Med. 2008;51(1):1-5. doi:10.1016/j.annemergmed.2007.07.008

3. Bursch B, Beezy J, Shaw R. Emergency department satisfaction: what matters most? Ann Emerg Med. 1993;22(3):586-591. doi:10.1016/ S0196-0644(05)81947-X
4. Trzeciak S, Rivers EP. Emergency department overcrowding in the United States: an emerging threat to patient safety and public health. J Emerg Med. 2003;20(5):402-405. doi:10.1136/emj.20.5.402

5. Clark RF, Hayden SR. The emergence of concierge emergency medicine. $J$ Emerg Med. 2013;45(6):915-916. doi:10.1016/j. jemermed.2013.07.017

6. Chang BP, Carter E, Suh EH, et al. Patient treatment in emergency department Hallways and patient perception of clinician-patient communication. Am J Emerg Med. 2016;34(6):1163-1164. doi:10.1016/j.ajem.2016.02.074

7. Centers for Medicare and Medicaid Services. Emergency department throughput measures stratification: numerator/denominator/exclusion calculation information; Available at: https://www.cms.gov/ Regulations-and-Guidance/Legislation/EHRIncentivePrograms/ Downloads/eCQM_LogicGuidance_v19_July2014.pdf. Accessed: 2/ 5/2020.

8. Partovi SN, Nelson BK, Bryan ED, Walsh MJ. Faculty triage shortens emergency department length of stay. Acad Emerg Med. 2001;8 (10):990-995. doi:10.1111/acem.2001.8.issue-10

9. Hoot NR, Aronsky D. Systematic review of emergency department crowding: causes, effects, and solutions. Ann Emerg Med. 2008;52 (2):126-136. doi:10.1016/j.annemergmed.2008.03.014.

10. Banner Health. ED door-to-doc toolkit; 2011. Accessed March 20, 2019.

11. Partovi SN, Nelson BK, Bryan ED, et al. Faculty triage shortens emergency department length of stay. Acad Emerg Med. 2001;8 (10):990-995. doi:10.1111/j.1553-2712.2001.tb01099.x

12. Holroyd BR, Bullard MJ, Latoszek K, et al. Impact of a triage liaison physician on emergency department overcrowding and throughput: a randomized controlled trial. Acad Emerg Med. 2007;14 (8):702-708. doi:10.1197/acem.2007.14.issue-8

13. Spencer S, Stephens K, Swanson-Biearman B, et al. Health care provider in triage to improve outcomes. J Emerg Nurs. 2019;45 (5):561-566. doi:10.1016/j.jen.2019.01.008

14. $\mathrm{R}$ Core Team. R: A Language and Environment for Statistical Computing. Vienna, Austria: $\mathrm{R}$ Foundation for Statistical Computing; 2018. Available from: https://www.R-project.org/.

15. Briggs WM. Reality-based probability $\backslash \&$ statistics: solving the evidential crisis (invited paper). Asian J Bus Econ. 2019;03(01):37-80.

16. Briggs WM. Everything wrong with P-values under one roof. In: Kreinovich V, Thach NN, Trung ND, Briggs WM. Everything wrong with P-values under one roof. In: Kreinovich $\mathrm{V}$, Thach $\mathrm{NN}$, Trung ND, Thanh DV, editors. It in Beyond Traditional Probabilistic Methods in Economics. NY, Springer. 2019:22-44.

17. Briggs WM, Nguyen HT, Trafimow D. The replacement for hypothesis testing. In: Kreinovich V, Sriboonchitta S, editors. Structural Changes and Their Econometric Modeling. Springer; 2019:3-17.

\section{Publish your work in this journal}

The Open Access Emergency Medicine is an international, peerreviewed, open access journal publishing original research, reports, editorials, reviews and commentaries on all aspects of emergency medicine. The manuscript management system is completely online and includes a very quick and fair peer-review system, which is all easy to use. Visit http://www.dovepress.com/testimonials.php to read real quotes from published authors. 